\title{
TopCom: Torneio de Programação
}

\section{Georgeana Monteiro de Oliveira Dias, Gustavo Storck Andrade de Souza, Gilmarllen Pereira Miotto, Felipe Branquinho Rodrigues, Douglas Funayama Tavares, Patrícia Dockhorn Costa}

\author{
${ }^{1}$ PET Engenharia de Computação - Universidade Federal do Espírito Santo (UFES) \\ Campus de Goiabeiras - Av. Fernando Ferrari \\ 29075-910 - Vitória - ES - Brasil \\ \{geanamonte, gustavo.storckl,gilmarllen\}@gmail.com, pdcosta@inf.ufes.br \\ \{felipebrangs, douglasfunay\}@gmail.com
}

\begin{abstract}
In order to foment advanced computing programming skills among computing students of the Espírito Santo state, the Computer Engineering Tutorial Educational Program (PET) group performs annually an event known as TopCom with the purpose of training for programming competitions. In this paper we discuss the development of such event and its impacts on the academy of the Espírito Santo state.
\end{abstract}

Resumo. Com o intuito de fomentar a programação avançada entre os alunos capixabas de informática, o Programa de Educação Tutorial (PET) de Engenharia de Computação da Universidade Federal do Espírito Santo (UFES) realiza anualmente o evento TopCom como um preparatório para competições de programação. Neste artigo são discutidos os processos para a realização de tal evento e sua importância para o meio acadêmico do Espírito Santo.

\section{Introdução}

Competições de programação são uma excelente oportunidade para desenvolver nos alunos diversas habilidades que serão extremamente úteis no seu crescimento profissional" [Campos and Ferreira 2004]. Assim sendo, o Torneio de Programação de Computadores (TopCom) foi o método que o Programa de Educação Tutorial (PET) Engenharia de Computação da UFES encontrou para promover essas competições entre os alunos dos cursos de Informática do Espírito Santo.

Ao seguir o modelo das competições nacionais e internacionais, o TopCom desperta nos alunos as habilidades de identificar tipos de problemas e programar rapidamente, além de melhorar suas capacidades de fazer análise de algoritmos e de codificar em uma específica linguagem. "O verdadeiro objetivo é o de produzir programadores completos mais capazes de implementar melhores softwares e solucionar complicados problemas de pesquisa na área da computação no futuro" [Halim and Halim 2013].

Criado em 1997 como um treinamento para as competições maiores, o TopCom se encontra hoje na sua $14^{\mathrm{a}}$ edição na qual contou com a participação de quase 100 alunos, de diferentes instituições do estado. A experiência em promover o evento propiciou o conhecimento necessário para organizar a Maratona de Programação ${ }^{1}$ (competição de

\footnotetext{
${ }^{1}$ website disponível em: http://maratona.ime.usp.br/
} 
renome nacional) em 2008, no qual ainda conseguimos a medalha de prata para o estado e a classificação para o mundial daquele ano.

Este artigo, então, procura informar todos os passos para a realização do evento e expor a evolução adquirida com os anos. A segunda seção detalha informações sobre o torneio, desde as etapas de planejamento, divulgação até sua realização. A terceira seção apresenta um dos desdobramentos do TopCom, o Steps, grupo de trabalho do PET focado em programação competitiva. A quarta seção relata o crescimento do evento ao longo dos anos. A quinta seção faz uma comparação com eventos correlatos e, finalmente, a sexta seção faz uma reflexão sobre as edições passadas do evento e vislumbra avanços para edições futuras.

\section{O Torneio}

O TopCom é um evento anual realizado entre maio e junho, e tem como principal motivação o incentivo à programação competitiva para os alunos da graduação e para os interessados de outras instituições de ensino, tanto do Médio quanto do Superior.

O formato utilizado é baseado nos torneios nacionais e internacionais de programação competitiva, como a ACM ICPC ${ }^{2}$. Procura-se simular ao máximo o ambiente oferecido por este torneio, utilizando questões, software e padrões de correção, para que os participantes possam experimentar um cenário real de competição e assim estarem familiarizados com as categorias de acesso da ACM ICPC.

\subsection{Planejamento}

Para a organização do evento é criado um grupo de trabalho, com cerca de cinco alunos do PET, que ficarão responsáveis por todos os processos referentes à realização do torneio. Com 4 meses de antecedência é feito o contato com os colaboradores: professores e egressos são contactados para o desenvolvimento das questões, visando cobrir os principais tópicos de programação competitiva como por exemplo, Problemas Ad-Hoc, Grafos, Paradigmas de Programação, Processamento de Strings, Estrutura de dados e Teoria dos números. Cada questão deve conter uma descrição do problema, arquivos com todos conjuntos de casos de teste, ou seja, entradas e saídas esperadas que serão utilizadas para validar a solução dos participantes, um arquivo com a solução do problema e com o tempo de resolução máximo para cada linguagem. Também é feito o contato com possíveis patrocinadores, no qual é apresentado o projeto e são estipulados planos de patrocínio. Os planos têm como vantagem a promoção de mão de obra especializada para as empresas e a divulgação de suas logos em camisas, sites, banners ou até mesmo em outdoor, tudo de acordo com o plano escolhido pelo patrocinador. É feita a reserva dos laboratórios de computação do departamento e uma sala que serão utilizados no evento, e também é estipulado o número máximo de alunos baseado na infraestrutura disponível.

Com 3 meses de antecedência, são convidados dois juízes para o evento, sendo um da UFES e o outro representando alguma instituição de ensino superior do Espírito Santo. A equipe de desenvolvimento WEB do PET começa o desenvolvimento do site e do sistema de inscrição; os responsáveis pelo design elaboram os modelos da camisa, dos banners e do outdoor. Com relação aos sistemas computacionais para o torneio, é preparada

\footnotetext{
${ }^{2}$ website disponível em: https://icpc.baylor.edu/
} 
a imagem que será instalada nos computadores a serem utilizados pelos participantes e o servidor que será responsável por toda gerência das questões, dos participantes, juízes, pontuação e correção dos problemas. Assim como nas maratonas nacionais, o software utilizado para gerenciamento do torneio (submissão, correção e acompanhamento das questões) é o $\mathrm{BOCA}^{3}$, discutido em mais detalhes na seção 2.3.

Faltando aproximadamente um mês para o evento, são fechados os patrocínios e finalizado o site onde é realizada a divulgação do evento, bem como através de cartazes presentes nas instituições de ensino próximas. Também são negociados o coffee break e a confecção das camisas.

\subsection{A agenda do torneio}

A agenda do dia do torneio consiste de atividades que ocupam o dia inteiro, geralmente um sábado. No primeiro momento é feita a entrega do material (camisetas e crachás) e o sorteio das máquinas. A equipe da organização então explica como utilizar o BOCA para submeter questões, ver resultados, etc. Em seguida, os competidores têm a oportunidade de treinar para o torneio, durante uma hora e meia (período denominado warmup), utilizando questões selecionadas pela equipe da organização. Além disso, o warm-up serve principalmente para testar a configuração das máquinas que serão utilizadas. A competição propriamente dita acontece depois do warm-up, durante um período de 5 horas. Logo após, todos os competidores, a equipe da organização e os jurados são convidados para o lanche, no qual os vencedores recebem a premiação, que é geralmente composta por troféus individuais para os três primeiros lugares e a inscrição gratuita das três primeiras equipes para a maratona regional de programação.

\subsection{BOCA}

O torneio é dividido em times formados por três participantes. Cada time tem o direito de trazer uma apostila para consulta e tem acesso a um único computador configurado com imagem de distribuições linux Ubuntu, na qual devem estar presentes ferramentas de desenvolvimento, como editores de texto, compiladores, e ambientes integrados de desenvolvimento; todo contato externo é bloqueado (internet e ssh).

Como discutido em [Campos and Ferreira 2004], "... é necessário que exista um mecanismo para a entrega dos programas em tempo real, já que a correção é feita durante a prova e a informação sobre o acerto ou erro deve ser passada assim que possível para o time.". Com esse intuito, o sistema BOCA tem sido utilizado para gerenciar a realização das últimas edições do TopCom.

Cada time tem um usuário no BOCA, no qual podem ver o conjunto de problemas disponíveis e suas respectivas descrições. A Figura 1 apresenta a tela do BOCA reservada para o gerenciamento dos problemas. O campo Name tem a finalidade de criar uma identificação curta para o problema. O campo Basename representa o nome esperado para classe que contém a main do programa. O Campo Fullname indica o nome completo do problema. E o Descfile possui um arquivo em pdf com a descrição do problema.

Para submeter uma solução, o time deve escolher o arquivo (.c, .cpp, .java), a questão correspondente e a linguagem de programação utilizada na solução daquela

\footnotetext{
${ }^{3}$ website disponível em: http://www.ime.usp.br/ cassio/boca/
} 


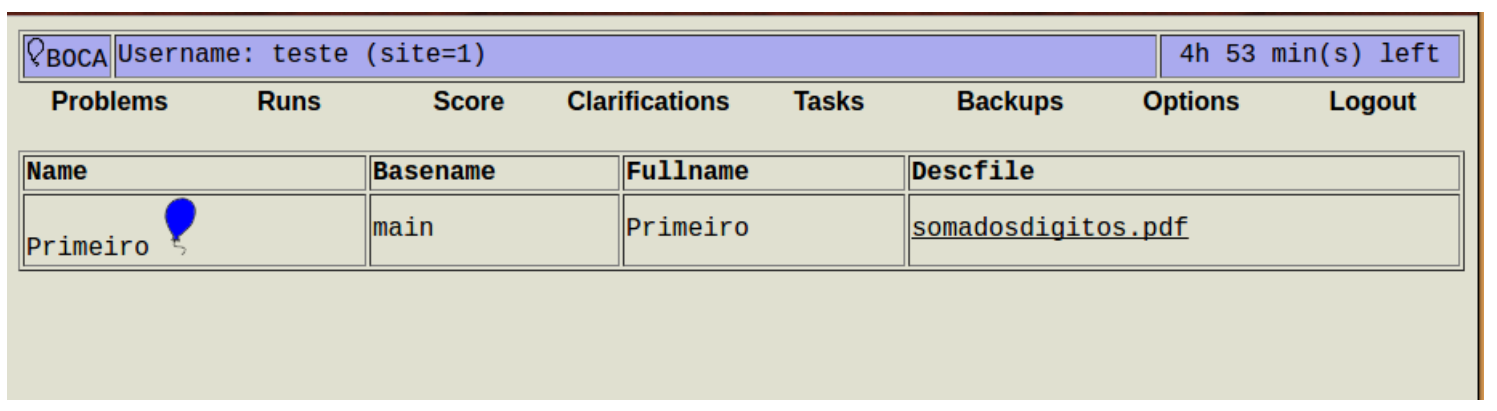

Figure 1. Problemas

questão em particular. Nas últimas edições do TopCom, as linguagens permitidas foram Java, $\mathrm{C}$ ou $\mathrm{C}++$.

A correção das questões pelo BOCA é baseada (i) em diff, ou seja, na diferença entre a saída do código fornecido e a saída esperada; e (ii) no tempo de execução entre a saída do código fornecido e a saída esperada. Após a correção da questão e da validação dos juízes, a resposta é fornecida. As repostas podem ser:

- Not answered yet: Resposta ainda não foi avaliada.

- YES: Resposta correta

- NO - Compilation error: Erro de compilação

- NO - Runtime error: Erro de execução

- NO - Time limit exceeded: A execução do programa ultrapassou o tempo esperado

- NO - Wrong answer: Resposta incorreta

Durante a competição, por meio do BOCA, as equipes podem ver sua pontuação em relação aos outros participantes, podem pedir para imprimir códigos e fazer perguntas ao juízes.

\subsection{Infraestrutura}

Na edição TopCom 14, em 2016, foi utilizada uma infraestrutura de três laboratórios de informática para os competidores e uma sala para os juízes, totalizando 33 computadores configurados com a imagem preparada para a competição, sendo um computador por equipe. Dois dos laboratórios são cedidos pelo Departamento de Informática (DI) da UFES e um deles por um dos grupos de pesquisa, do mesmo departamento. O PET articula uma colaboração com a equipe do suporte ${ }^{4}$ do DI para manter o bom funcionamento da rede, dos computadores e de todo o ambiente computacional. O servidor do sistema BOCA é hospedado em um dos servidores do suporte e, portanto, é fundamental que o PET e o suporte trabalhem juntos na configuração do servidor e no apoio no dia da competição.

\section{Steps}

Como um dos desdobramentos do TopCom, criou-se em 2011 no PET Eng. Computação um grupo de trabalho denominado Steps, que tem por objetivo estimular o interesse e aperfeiçoar os conhecimentos em programação competitiva. Visando obter boas

\footnotetext{
${ }^{4}$ website disponível em: http://suporte.inf.ufes.br/
} 
colocações em competições, os membros deste grupo estudam e praticam os assuntos de possíveis questões de competição: Ad-hoc, Strings, Estruturas de Dados, Matemática, Paradigmas e Grafos. A base do treinamento é a submissão de questões aos juízes online semelhantes aos utilizados nas competições, em principal o URI Online Judge (URI), e o Sphere Online Judge (SPOJ) ${ }^{5}$. Em paralelo à isso, à partir do $3^{\circ}$ período da graduação, os alunos têm a oportunidade de realizar uma disciplina optativa oferecida pelo Departamento de Informática, que tem como objetivo estimular e preparar os alunos para a participação na Maratona ACM ICPC, e que por isso tem como ementa o estudo dos principais assuntos da área de programação competitiva.

\subsection{Participação em Competições}

Atualmente, as competições nas quais os membros do Steps participam são: o TopCom, tratado neste artigo, e a Maratona ACM ICPC, competição de âmbito internacional mais importante da área. Historicamente, já foram obtidos excelentes resultados com a participação das equipes com membros Steps nas competições. Por exemplo, nos anos 2011, 2012 e 2013 a equipe Steps classificou-se para a fase nacional da Maratona ACM ICPC, e nas duas últimas edições do TopCom, a equipe vice-campeã era uma equipe Steps.

\subsection{Ensino: preparatório para a OBI}

Além da pesquisa e treinamento, os membros do grupo Steps também realizam atividades de ensino: o Preparatório para a Olimpíada Brasileira de Informática (OBI) ${ }^{6}$. O PET Eng. de Computação tem como um de seus principais projetos o Introcomp [Oliveira et al. 2014], que consiste de um curso de programação de computadores destinado à alunos de ensino médio da rede pública, que é realizado anualmente no segundo semestre do ano.

Nos seis meses que precedem o curso do Introcomp, é iniciado o preparatório para a OBI, no qual é ofertado aulas para alunos do ensino médio da rede pública (em geral, alunos do Introcomp do ano anterior) que queiram competir nas modalidades de Programação. A OBI, organizada pelo Instituto de Computação da UNICAMP, é uma competição nos moldes das outras olimpíadas científicas brasileiras, com medalhas como forma de premiação para os alunos mais bem colocados. A competição exige conhecimentos aprofundados em algoritmos de programação de computadores, com questões de níveis fáceis até mais complexos.

Realizado desde 2012, o Preparatório já obteve excelentes resultados na OBI. Até hoje, foram sete medalhas no total entre os níveis 1 e 2, com destaque para as medalhas de ouro no nível 1 em 2012 e no nível 2 em 2014. Também em 2014, foi obtida Medalha de Prata na competição internacional International Olympiad in Informatics ${ }^{7}$.

Em geral, os alunos do Preparatório também participam do TopCom obtendo boas colocações, como no TopCom14 em que uma equipe formada por alunos do Preparatório ficou em $9^{\circ}$ lugar.

\footnotetext{
${ }^{5}$ website disponível em: https://www.urionlinejudge.com.br/ e http://br.spoj.com/

${ }^{6}$ website disponível em: http://olimpiada.ic.unicamp.br/

${ }^{7}$ http://www.ioinformatics.org/index.shtml
} 


\section{Histórico e Estatísticas}

O TopCom é um torneio com 19 anos de história, e tem proporcionado representatividade para o Espírito Santo em âmbito nacional, na área de programação.

Em suas primeiras edições, em 1997 e 1999, o torneio ainda era voltado para alunos dos cursos de Ciência e Engenharia de Computação da UFES. As linguagens de programação permitidas eram C, Pascal e Modula-2 e a premiação era 15 horas de acesso à Internet. Além disso, todo o processo de gerenciamento do torneio (submissão e correção das questões, acompanhamento dos juízes, etc.) era feito manualmente, sem o apoio de um sistema como o BOCA.

Em sua terceira edição, em 2004, alunos de outras instituições puderam participar do torneio. As linguagens $\mathrm{C}++$ e Java passaram a ser permitidas e o evento começou a financiar a participação das equipes vencedoras na Maratona de Programação. A partir de 2006, o evento passou a ser anual. Em sua quinta edição, em 2007, a equipe vencedora do TopCom ganhou a inscrição para a regional da Maratona de Programação e saiu vencedora desta fase. A mesma equipe conseguiu a $14^{\mathrm{a}}$ posição na fase nacional.

No TopCom 6, em 2008, a equipe vencedora, constituída de alunos da UFES, conquistou o $4^{\circ}$ lugar na final nacional da Maratona de Programação, e participou, portanto, da final mundial em Estocolmo, na Suécia. Em 2009 duas das quatro primeiras equipes vencedoras foram classificadas para a final nacional da Maratona de Programação, destacando o Espírito Santo com dois times entre os 51 melhores do Brasil. De 2010 a 2012, o TopCom contou com o patrocínio da ISH Tecnologia, uma importante empresa de TI do estado. As equipes vencedoras de cada uma destas edições conseguiram novamente a vaga para a final nacional da Maratona de Programação, conquistando então $15^{\circ}, 23^{\circ}$ e $30^{\circ}$ lugares, respectivamente.

A partir de 2013, equipes compostas de alunos do ensino médio começaram a se destacar nos torneios, conseguindo boas colocações, inclusive primeiros lugares. Notase que boa parte das equipes de ensino médio vencedoras são compostas por alunos do Introcomp [Oliveira et al. 2014], curso de programação oferecido anualmente pelo PET. Com o passar dos anos, o TopCom tornou-se uma competição bastante atrativa, como ilustra o gráfico apresentado na Figura 2, que mostra o número de equipes participantes nas 14 edições do evento. Em 2016, em sua 14 a edição, o TopCom teve recorde de inscritos, totalizando 33 equipes (99 participantes).

O gráfico da Figura 3 ilustra a participação das diferentes instituições do estado no TopCom 14, em 2016. Observa-se a participação dos campi da UFES de São Mateus e Alegre (localizados ao norte e ao sul do ES, respectivamente), dos campi do IFES e dos alunos do preparatório OBI/Introcomp (cursos fornecidos pelo PET - Engenharia de Computação).

A Tabela 1 detalha o desempenho das equipes no TopCom 13, comparando a quantidade de questões resolvidas pelas equipes das diferentes instituições (foram propostas 10 questões nesta edição do TopCom). A tabela destaca os alunos da UFES que fizeram a disciplina de programação competitiva oferecida pelo Departamento de Informática da UFES (TEP), para os cursos de Ciência e Engenharia de Computação. As demais colunas informam a quantidade de equipes, a quantidade máxima e mínima de questões resolvidas, a média e o desvio. O desvio nos informa o quanto a média é confiável, ou seja, 


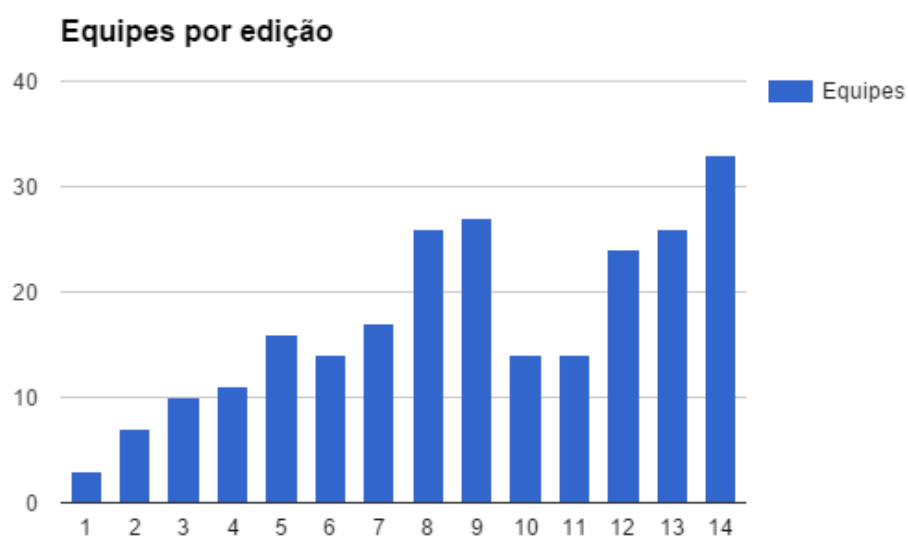

Figure 2. Gráfico de equipes participantes por edição

Table 1. Quantidade de questões resolvidas por instituição (TOPCOM 13)

$\begin{array}{cccccc}\text { Instituição } & \text { Equipes } & \text { Max } & \text { Min } & \text { Média } & \text { Desvio } \\ \text { CCA } & 4 & 2 & 0 & 1 & 1.155 \\ \text { CEUNES } & 2 & 4 & 0 & 2 & 2.823 \\ \text { IFES } & 4 & 8 & 0 & 2.75 & 3.594 \\ \text { UFES } & 12 & 4 & 0 & 1.5 & 1.314 \\ \text { TEP } & 4 & 7 & 1 & 3.25 & 2.63\end{array}$

com desvios baixos a média é mais confiável do que com desvio altos. Com isso podemos concluir que os alunos da disciplina TEP tiveram um melhor desempenho no torneio, pois a média de questões resolvidas foi a maior e seu desvio foi menor do que as médias do IFES e CEUNES.

\section{Eventos Correlatos}

Existem várias iniciativas nacionais e internacionais correlatas ao TopCom. A Maratona Mineira de Programação ${ }^{8}$, por exemplo, é uma competição de programação similar ao TopCom organizada pelas instituições de ensino de Minas Gerais. É um evento um pouco mais recente, com 5 edições até o ano de 2016. O objetivo do evento é o mesmo do TopCom para a região do Espírito Santo: motivar e preparar as equipes estaduais para a Maratona de Programação SBC. As regras para elegibilidade de um competidor seguem as regras da Maratona ICPC. Assim, existem algumas diferenças em relação ao Topcom, já que somente competidores elegíveis para uma possível fase regional da Maratona de Programação SBC estão aptos a participar do evento. Já no Topcom, não existem regras restringindo a participação dos competidores, fazendo com que alunos de qualquer instituição de ensino e período possam participar da competição. O sistema de correção utilizado também o BOCA.

Um exemplo de evento internacional similar ao TopCom é o Virginia Tech High

\footnotetext{
${ }^{8}$ website disponível em: http://maratonamineira.uniube.br/
} 


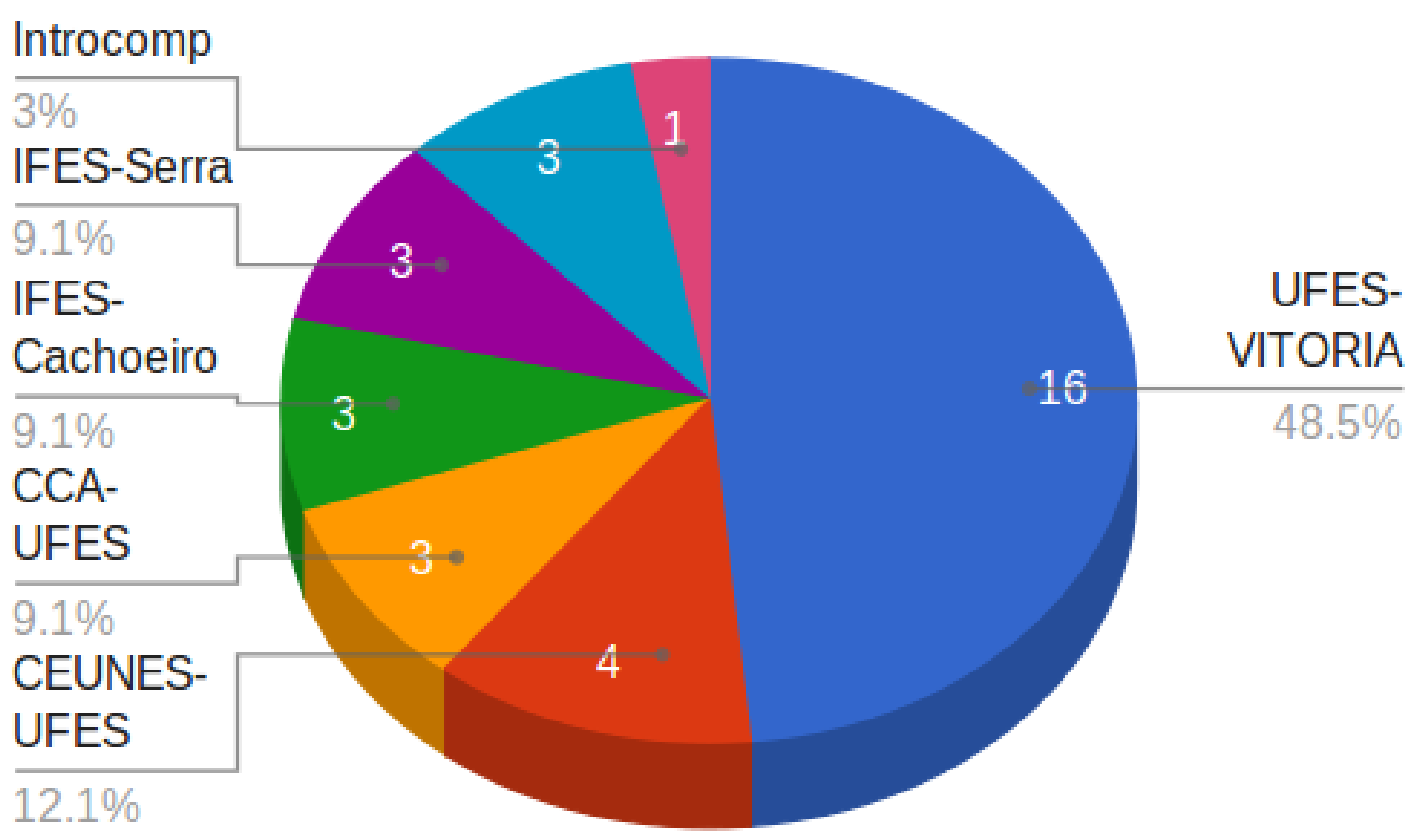

Figure 3. Gráfico de equipes participantes separadas por instituições ou grupos (TopCom 14)

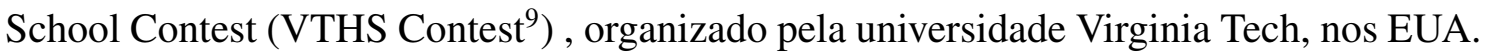
O principal intuito da competição é treinar as equipes das faculdades do estado americano para a ACM ICPC. O evento encontra-se em sua terceira edição e a última contou com 101 equipes participantes. Diferentemente do TopCom, o VTHS Contest exige a participação de um professor (coach) como representante da equipe, seguindo as regras oficiais da ACM ICPC. Outra diferença é que o VTHS Contest é realizado online e não possui limite de equipes participantes, já que não são limitados pelo espaço físico e materiais para a realização do evento. Seria interessante considerar a viabilidade deste modelo para o TopCom, já que atualmente o crescimento da competição está limitado a estes fatores.

Um outro exemplo de evento correlato é a Maratona de Programação da Universidade Federal do Mato Grosso - Rondonópolis ${ }^{10}$, realizada como uma das várias atividades do Congresso de Computação do Sul de Mato Grosso (COMPSULMT). Diferentemente do TopCom, nesta competição existem duas categoria, programação básica e avançada. Além disso, as equipes podem ser compostas de um a três membros, não seguindo o formato das competições nacionais e internacionais. Outras diferenças estão relacionadas ao modelo da competição, no qual não é possível levar material impresso e as linguagens de programação permitidas são C e Pascal. A categorização da competição em básica e avançada é interessante e pode ser considerada no TopCom a fim de incentivar a participação dos calouros.

Um outro evento relacionado ao TopCom é a Maratona de Programação SEC$\mathrm{OMP}^{11}$, realizada pelo PET Computação da Universidade Estadual do Ceará. O modelo desta competição é muito similar ao TopCom. No entanto, a última edição da competição

\footnotetext{
${ }^{9}$ website disponível em: https://icpc.cs.vt.edu/\#/

${ }^{10}$ website disponível em: http://www.compsulmt.com.br/maratona.html

${ }^{11}$ website disponível em: http://www.secomp.uece.br/maratona-de-programacao/
} 
limitou para apenas 7 o número de equipes participantes. Considerando os eventos citados acima, e outros encontrados na Internet, o TopCom tem acompanhado as tendências no que concerne aos modelos das competições, infraestrutura oferecida e premiações. Com relação à premiações, uma particularidade do TopCom é oferecer às três primeiras equipes as inscrições na maratona regional de programação (além de troféus e outros prêmios), incentivando assim, a participação dos alunos nas competições nacionais.

O modelo de competição online do evento internacional VTHS Contest é interessante e deve ser estudado pelo grupo PET para próximas edições do TopCom. Deve-se considerar, é claro, a realidade dos competidores brasileiros que podem não dispor da infraestrutura necessária para participar do evento.

\section{Conclusões e Perspectivas Futuras}

O TopCom é um torneio com 19 anos de história, e tem fomentado o interesse dos estudantes nas competições de programação, refletindo assim em uma maior participação do Espírito Santo em competições de programação nacionais e internacionais. Desde sua primeira edição, em 1997, o número de participantes tem aumentado, assim como também tem crescido a participação de diferentes instituições de ensino do estado. Em 2016, em sua $14^{\text {a }}$ edição, o TopCom teve recorde de inscritos, totalizando 33 equipes (99 participantes).

Desde sua terceira edição, em 2004, como parte da premiação, o TopCom financia a inscrição das equipes vencedoras na etapa regional da Maratona de Programação. Em praticamente todas as edições do evento, as equipes vencedoras tiveram bons resultados na etapa regional e foram classificadas para a final nacional. Portanto, o TopCom desempenha um papel fundamental no nosso estado ao incentivar os alunos locais a participarem da Maratona de Programação. A medalha conquistada em 2008 na fase nacional da Maratona e a participação no mundial em Estocolmo naquele ano confirmam a importância do TopCom como treinamento e incentivo para os competidores capixabas.

O grupo de trabalho Steps, um dos desdobramentos do TopCom, também tem desempenhado um papel importante no nosso estado, oferecendo treinamento e incentivando a participação do alunos capixabas na Olimpíada Brasileira de Informática (OBI). Desde o início do treinamento, em 2012, os alunos obtiveram excelentes resultados na OBI: sete medalhas no total entre os níveis 1 e 2, incluindo duas medalhas de ouro. Em 2014, um dos alunos que fez o treinamento obteve Medalha de Prata na competição internacional International Olympiad in Informatics, inédita para o estado.

Como discutido em [Burguillo, 2010], [Digiampietri et al., 2014], [Piekarskie et al., 2015] e em vários outros trabalhos, a dinâmica de competições amigáveis pode ser utilizada como forma de estimular o aprendizado de conceitos de programação. Por meio do TopCom, o PET apoia os cursos de Engenharia e Ciência da Computação da UFES estimulando o desenvolvimento de habilidades de programação entre os alunos, oferecendo um ambiente amigável de competição. Observou-se ao longo dos anos grande participação dos alunos (inclusive calouros) nas competições. Obviamente, os talentos são revelados e geralmente saem premiados das competições. No entanto, observa-se entusiasmo dos alunos de uma forma geral, mesmo dos alunos que não se destacam nas competições. Estes alunos têm procurado se aperfeiçoar na disciplina de programação competitiva, e costumam participar de várias edições do TopCom. 
Com o crescimento do TopCom ao longo dos anos, os maiores desafios encontrados pelo PET no que concerne à organização do evento estão relacionados à infraestrutura (espaço físico e configuração do ambiente computacional). Com o intuito de permitir o crescimento do evento e, ao mesmo tempo, manter a qualidade esperada, o PET vem aperfeiçoando as etapas de planejamento. Por exemplo, têm sido articuladas parcerias com os laboratórios de pesquisa do Departamento de Informática (DI), em busca de mais espaço físico para execução das competições, e com o grupo do Suporte do DI, para apoiar a configuração dos sistemas computacionais (rede, máquinas e servidores). Além disso, todos os processos do desenvolvimento do evento são documentados em uma wiki, para que futuras gerações de Petianos possam continuar organizando o TopCom com melhorias incrementais.

\section{References}

Burguillo, J. C. (2010). Using game theory and competition-based learning to stimulate student motivation and performance. Computers \& Education, 55(2):566-575.

Campos, C. P. and Ferreira, C. E. (2004). Workshop de educação em computação (brazilian workshop on education in computing). Anais do Congresso da SBC.

Digiampietri, L. A., Peres, S. M., Nakano, F., Roman, N. T., Wagner, P. K., Silva, B. B. C., Teodoro, B., da Silva Jr, D. F. P., Pereira, G. V. A., Borges, G. O., et al. (2014). Complementando o aprendizado em programação: Revisitando experiências no curso de sistemas de informação da usp. iSys-Revista Brasileira de Sistemas de Informação, 6(1):5-29.

Halim, S. and Halim, F. (2013). Competitive Programming 3: The New Lower Bound of Programming Contests: Handbook for ACM ICPC and IOI Contestants. Lulu. com.

Piekarski, A. E., Miazaki, M., Hild, T., Mulati, M. H., and Kikuti, D. (2015). A metodologia das maratonas de programação em um projeto de extensão: um relato de experiência. In Anais dos Workshops do Congresso Brasileiro de Informática na Educação, volume 4, page 1246.

Valentim, R., Meneses, L., Carvalho, T. M., Penha, R. E., de Oliveira, P., dos Santos, G. A., Rodrigues, L. P., Leite, L. B., Rodrigues, D. P., Gomes, R. L., et al. (2014). Em busca de uma metodologia para a disseminaçao em massa do ensino de programaçao. Seminário Nacional de Inclusao Digital (SENID), Passo Fundo, RS, SBC. 